\title{
The Study of Credit Risk Stress Testing on Micro-credit Companies
}

\author{
Meijuan $\mathrm{He}^{*}$ \\ Zhejiang University of Finance and Economics, China \\ Hemeijuanx@163.com
}

\begin{abstract}
Keywords: Small loan; Credit risk; Stress testing
\end{abstract}
\begin{abstract}
With the deterioration of the external economic environment in recent years, the problem of credit risk in China's economy has gradually been exposed. We carries out credit risk stress testing on small loan companies in Zhejiang province with macro stress testing framework of financial system. The results show that the fluctuations of nominal GDP growth rate significantly affect loan delinquencies of small loan companies, and it is necessary to make an eye on macro-economy fluctuation when we are monitoring the risk of small loan companies.
\end{abstract}

\section{Introduction}

The World Bank Advisory Group on Poverty Alleviation (CGAP) defines that micro-credit companies provide loans, deposit and remittances and other financial services for low-income families. Micro-finance is an effective complement to the formal banking system. Non-depository financial institutions provide capital to groups that are excluded by the formal banking sector, in low transaction costs and flexible lending methods (Zhang Longyao, 2016) [1].

At present, the study of micro-finance in the mainland of China mainly starts with the development of small-loan companies. For example, Liu Haijuan (2016) puts forward that micro-credit companies are an important complement to financial institutions and have solved the funding needs of some SMEs while promoting the development of the entire financial industry [2]. However, research on credit risk management of micro-credit companies starts late, and existing studies are still discussing credit evaluation. For example, Yan Xue and Lu Jiliang (2010) put forward establishing credit evaluate system for small-loan companies[3]. In fact, stress test as a main mean of risk prevention in modern financial institutions, are rarely applied to small-loan companies.

\section{Research Review}

The International Organization of Securities Commissions (IOSC) pointed out that Stress Testing analyzes the effect on the portfolio of assets under the assumption that the market is under extremely adverse conditions. The International Monetary Fund (IMF) and other agencies think Stress testing refers to use a set of methods to assess the risk resilience of financial systems under abnormal macro-economic shocks (Chen Weidong et al., 2015) [4]. In general, organizations such as the BCBS, BCGFS and China Banking Regulatory Commission, all have similar definitions of stress tests, and they also put forward applying stress tests regularly on financial institutions such as banks to measure the stability of the financial system. At the same time, stress testing can be divided into micro-stress test and macro stress test according to the different test objects. Micro stress test prefers specific portfolio test (IOSC, 1995), it dedicated to test the changes of portfolio value under extreme adverse market conditions and macro stress test prefers the entire financial system testing, the IMF, BCBS, BCGPS and CBRC use to test the stability of the financial system. At present, the stress tests conducted by financial institutions mainly focus on macro stress tests, covering the tests of various aspects of the stability of financial institutions.

Since the outbreak of the sub-prime crisis in the United States in 2007, stress testing has become the primary measure of risk measurement in the financial industry. For example, the Basel Capital Accord (2009) required banks to conduct stress tests regularly to estimate the potential losses of 
banks in order to identify risks. The United States conducted capital adequacy tests on 19 large banks in February 2009. And in Europe, 91 banks were stress-tested in 2010. China Banking Regulatory Commission (2004) specified the design and implementation targets of stress tests. Subsequently, they respectively conducted stress tests on real estate loans and liquidity of small and medium banks in 2007 and 2008. In 2017, the "Amendment of Liquidity Measures of Commercial Banks" made it clear that stress tests should be conducted regularly, which further sets the requirements for the banking industry. So, stress testing has become a major measure of the stability of the financial system, and many academics have been attracted to conduct corresponding research.

Foreign Research Results. As early as the 1990s, foreign countries have put forward the concept of stress testing, emphasizing the importance of stress testing and gradually it was used to measure the stability of the financial system.

There are so many overseas scholars' research achievements in stress testing and some scholars pay attention to macroeconomic variables that affect the financial system risk, also a considerable number of scholars focus on the risk model of stress testing. Of course, many research results involve these two aspects, setting up the risk model of stress test will also consider the setting of the influencing factors of the model after all.

In terms of macroeconomic factors, Pesola (2000) used empirical data of Finland to study the sensitivity of the banking system to macroeconomic fluctuations[5]. Deventer et al. (2005) analyzed a number of large multinational banks found that macro-factors affect the credit thus affect the bank credit risk[6]. Rodriguez et al. (2007) studied various factors that affect the credit risk of Spanish loans, such as loan types and economic cycles[7].

For the stress testing model, Wilson (1997a, 1997b) established a credit portfolio risk model to fit the expected probability of default under the influence of macroeconomic fluctuations[8,9]. Berkowitz Jeremy (1999) believed that stress tests should use a risk model and take into account the probability of scenario occurrence[10]. Boss (2002) found that macroscopic factors such as industrial output, inflation, stock price index, short-term interest rate changes and oil price changes have a significant impact on the default rate of Australian companies[11]. Virolainen (2004) established the Bank of Finland's macroeconomic credit risk model based on Wilson (1997a, 1997b) and carried out the corresponding stress test analysis[12]. Kearns (2004) Conducted a macroeconomic stress test on Irish retail credit agencies[13]. Wong et al. (2008) conducted stress tests on retail banks in Hong Kong by introducing macroeconomic variables such as GDP, real estate prices and interest rates[14]. And Avouyi-Dovi S. et al. also used the research framework of Wilson (1997a, 1997b) to construct a stress test module for the French manufacturing industry using two scenario assumptions[15].

Domestic Research Results. Mainland scholars on the stress test research according to the type of stress test can mainly be divided into two types, macro stress tests and micro stress tests.

The research on macroscopic stress test can be mainly divided into two kind, the summary of the methods and development of stress testing, and the empirical analysis results of the stress test of the financial system. Among these achievements, apart from Shusong Ba and Yuanqian Zhu (2010) introduced macro stress tests[16], Jun Yin and Shuang Liu (2011) and Jiangang Peng et al. (2015) described the application of stress testing combining with macro-prudential regulatory framework[17][18]. More researches focused on the empirical tests of stress tests. For example, Jianjun Shi and Yuan Zhou (2011) used SVAR model to test Jiangsu's bank sector[19]. It was found that the risk of credit loans will make the banking industry earnings dropped significantly. Shenggang Yang and Yazhi Liu (2015) conducted stress tests by using the data of 4 state-owned banks and 7 joint-stock commercial banks to find out the prevailing liquidity risk[20]. Industrial and Commercial Bank of China Environmental Stress Test Group (2016) conducted a research on commercial bank risk for the first time through the perspective of the cost of the enterprise environment[21]. It is believed that the internalization of environmental costs will help to improve the risk prevention and control ability of banks. Shiying Gao et al. (2016) based on the "new normal" economic background, selected the data from 2006 to 2014 of 16 listed banks in China, founding that the proportion of non-interest income has a great influence on the liquidity of 
commercial banks in China[22]. Ding et al. (2016) suggested that stress tests should be included in the daily operation of commercial banks and risk management framework[23]. Xiaoqin Tan (2017) found that under the framework of FSAP, setting mild and severe scenarios of GDP and CPI, the stability of the banking sector decreased significantly[24]. Fang Yi (2017) designed a real estate loan defaults, local government financing platform loan defaults, bank failures to analyze impact on the banking sector macroeconomic systemic risk[25].

Studies on micro stress testing is less. Most scholars mainly focus on real estate loans. Such as Yangmin Zhou (2014) tested real estate companies based on the impact of the purchase order, real estate tax and the new land policy[26]. Zhang Yan and Nan Duan (2015) conducted real estate stress test by using Merton-Vasicek model on China's small and medium commercial banks[27]. Yuxi Gao (2016) studied the macro conduction mechanism of real estate credit risk, and analyzed the macro-economic under extreme conditions[28]. The result showed that real estate market would cause higher ratio of the bad debt.

Overall, stress test in the financial system has been achieved in both the theoretical and practical sectors, but for micro-credit companies such as small finance companies, not only researches of risk management lack of study, but also the common research means of risk prevention in the financial system such as stress testing has not been popularly applied to small and micro financial institutions as small loan companies. Therefore, we will conduct model based on the data of Zhejiang Province micro-loan companies and establish a macro-stress test framework to prevent private financial liquidity risk earlier.

\section{Methodology and Data}

Method. According to the commonly used methods of macro stress test, it can be divided into the sensitive analysis method and the scenario hypothesis method. Sensitive analysis usually only assumes a single major risk factor influence the financial system. For example, the change of one risk factor leads to the change of the value of the asset portfolio, thus to understand the financial system's ability to withstand the impact of changes in the risk factors. The scenario hypotheses examine the impact of multiple risk factors simultaneously on the financial system. Assuming multiple risk factors change at the same time, such scenarios can often refer to historical events (historical scenarios) or use experts to assume that some events (hypothetical scenarios) have not occurred yet. From the existing research, most of them use scenario hypotheses, and scholars likely t examine the impact of multiple risk factors on the banking system or an asset portfolio when they change simultaneously.

The methods of risk measurement generally fall into the categories of Top-down Approaches and Bottom-up Approaches. The former estimates the cost or loss brought by the risk event from the financial system, the latter analyzes the operation flow from the single service type or loss event to manage the cost or loss caused by the event. The current research results mostly based on Top-down risk measurement, but in fact the Basel Accord based on the top-down approach.

Therefore, the stress test mode of the micro-credit company is also designed by the scenario hypothesis method, and the risk measurement method is carried out by the Top-down method. The initial assumption of stress test process be shown in Fig. 1.

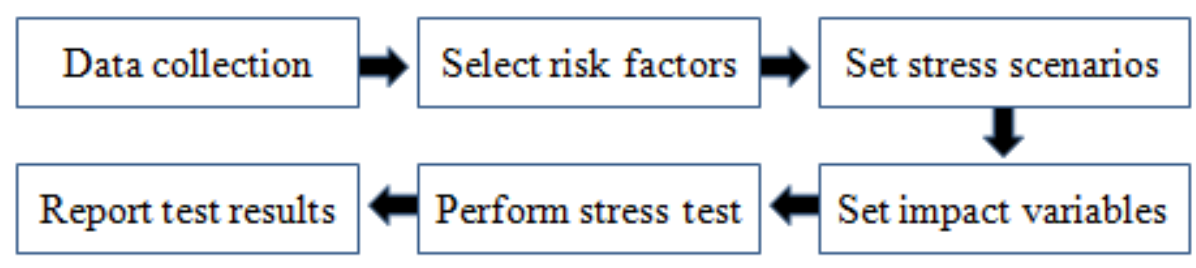

Figure 1. Pressure test a simple process

Data. In July 2008, the Zhejiang Provincial Government formulated "the Opinions on Implementing the Pilot Project for Small Loan Companies". The provincial government finance 
office and the Provincial People's Bank, the Banking Regulatory Bureau and the Bureau of Industry and Commerce jointly issued and promulgated the "Pilot Projects Interim Measures for Zhejiang Small Loan Company". The formulation and promulgation of the two documents have promoted the pilot project of micro-finance companies in Zhejiang Province in an orderly manner. Before December 31, 2010, there were 134 small loan companies in Zhejiang with a total registered capital of 22.583 billion. A total number of 93,750 loans were issued, 111.47 billion yuan. We collect macro monthly data of Zhejiang Province from 2009 to 2010 according to Zhejiang Provincial Bureau of Industry and Commerce, Zhejiang Provincial Bureau of Statistics, National Bureau of Statistics, China Economic Net and so on, and collects corresponding micro-credit company cycle data from the annual supervision report of small loan company of Zhejiang. Select risk factor and establish stress scenarios to ensure the stress test be conducted.

Model. Firstly, select the risk factors. From the existing results, the most commonly used risk factors for macro stress testing are Probability of default (PD), Loss Given Default (LGD) and Exposure at Default (EAD). Micro-finance companies are mainly engage in small loans, and their risks are mainly concentrated in the credit risk of loans. Micro-finance companies "loan with no-deposit", lack of financing channels, loans can be relatively fixed. Loans overdue will affect the funding cycle and loan quality, resulting in serious credit risk. According to the risk characteristics of micro-loan companies and the availability of data, this paper selects the loan overdue ratio which is closely related to the probability of default as an influencing factor.

Secondly, in the selection of models, the existing achievements are mainly based on the model of Wilson (1997a, 1997b). Wilson (1997a, 1997b) uses Logistic model to convert the default overdue rate into an intermediary indicator $\mathrm{K}$. This will ensure that the predicted loan overdue rate is between $0-1$. Therefore, letting the loan overdue rate be $\mathrm{P}$, the available intermediary index $\mathrm{K}$ is as shown in Eq.1.

$$
K=\ln \left(\frac{P}{1-P}\right)
$$

Based on the model set by Wilson (1997a, 1997b), the chosen multivariate linear regression model is shown in Eq.2.

$$
\ln \left(\frac{P_{t}}{1-P_{t}}\right)=\beta_{0}+\beta_{1} x_{1 t}+\beta_{2} x_{2 t}+\Lambda+\beta_{n} x_{n t}
$$

$\mathrm{P}_{\mathrm{t}}$ is the loan overdue rate during the period $\mathrm{t}$ and $\mathrm{x}$ is the corresponding macroeconomic variable for period t. Eq. 2 can be converted into Eq.3 and Eq.4.

$$
\begin{aligned}
& P_{t}=\left(1-P_{t}\right) e^{\beta_{0}+\beta_{1} x_{1 t}+\beta_{2} x_{2 t}+\Lambda+\beta_{n} x_{n t}} \\
& P_{t}=\frac{e^{\beta_{0}+\beta_{1} x_{1 t}+\beta_{2} x_{2 t}+\Lambda+\beta_{n} x_{n t}}}{1+e^{\beta_{0}+\beta_{1} x_{1 t}+\beta_{2} x_{2 t}+\Lambda+\beta_{n} x_{n t}}}
\end{aligned}
$$

Accordingly, the establishment of macroeconomic factors as explanatory variables, we can start scenario analysis of $\mathrm{P}_{\mathrm{t}}$.

Stress Scenarios Established. Combining with the existing achievements and the characteristics of small loan companies facing private finance, we select nominal GDP growth rate, CPI growth rate, PPI growth rate, the total retail sales of social consumer goods and rural resident income these five variables as macroeconomic factors which affect loan overdue rates.

GDP growth rate. Gross Domestic Product is an indicator of the state of the economy. The growth rate of gross domestic product in a region has an important influence on the economic development in the region, which indicates the future direction of economic development, also an important indicator of the solvency of individuals involved in the operation of an economic system.

CPI growth rate. Consumer Price Index is an important indicator of inflation. If the inflation rate increases, borrowing costs increase, the possibility of overdue loans and defaults on loans will 
increase.

PPI growth rate. Producer Price Index is used to measure the manufacturer's ex-factory price of the average change index. It may affect the CPI growth rate by its own change, thus affecting the borrower's repayment.

The total retail sales of social consumer goods. It reflects the degree of realization of the purchasing power of social goods in a certain period, the strong purchasing power of social goods, the good consumption status, the steady economic situation and the reduced possibility of overdue loan and default.

Rural resident income. It can reflect the living conditions of local rural residents. Micro-finance companies are mainly target at "agriculture, rural areas and farmers" and SMEs. The increase of rural residents' income will bring about the repayment intention of rural borrowers and also will affect loan overdue.

At the same time, according to these five variables we set the pressure scenarios in Table 1.

Table 1. Assumes a stress scenario event

\begin{tabular}{llll}
\hline \multirow{2}{*}{ Pressure variable } & \multicolumn{3}{l}{ Stress scenarios } \\
\cline { 2 - 4 } & Mild[\%] & Moderate[\%] & Severe[\%] \\
\hline Nominal GDP growth rate & -10 & -20 & -30 \\
CPI growth rate & 10 & 20 & 30 \\
PPI growth rate & 10 & 20 & 30 \\
The total retail sales of social consumer goods (S) & -10 & -20 & -30 \\
Rural resident income (FI) & -10 & -25 & -40 \\
\hline
\end{tabular}

\section{Results}

Model Fitting. According to the established model, regression analysis is made on the selected macroeconomic variables in Zhejiang Province. By excluding the variables with insignificant impact on the loan overdue rate, the explanatory variables that ultimately determine the interpretation model of the credit risk stress test of the micro-loan company are the nominal GDP growth rate, the CPI growth rate and the total retail sales of social consumer goods, and the calculation results of the model fitting are shown in Table 2.

Table 2. Pressure test model fitting results

\begin{tabular}{lllll}
\hline Variable & Constant & NGDP & CPI & S \\
\hline Coefficient & -5.424 & -0.109 & 0.083 & -0.00009706 \\
$t$-statistics & $-9.400^{* *}$ & $-3.123^{* *}$ & $1.925^{*}$ & $-2.290^{* *}$ \\
\hline
\end{tabular}

Note: $* *$ indicates significant at 0.05 confidence level; * indicates significant at 0.10 confidence level.

From the results of Table 2, the three variables have a significant impact on loan overdue rates, which is in line with the analysis of the impact of these variables. However, the impact of PPI and rural residents' income on overdue loans is insignificant. The former may be related to the opposite trend of CPI and PPI in 2009, the latter reflects the fact that the loan object of the small loan company in Zhejiang Province may not completely related to "agriculture, rural areas and farmers". Therefore, according to the Eq.4, we construct the pressure test model as shown in Eq.5.

$$
P_{t}=\frac{e^{-5.424-0.109 N G D P+0.083 C P I-0.00009706 S}}{1+e^{-5.424-0.109 N G D P+0.083 C P I-0.00009706 S}}
$$

Stress Scenario Analysis. According to the hypothetical scenario in Table 1 and the data of micro-credit Company of Zhejiang Province in December 2010, the impact of the three 
macroeconomic variables is calculated respectively to examine the influence of each scenario on the overdue rate of microfinance companies in Zhejiang Province. The results are shown in Table 3.

Table 3 Assumed scenario stress test results

\begin{tabular}{lllllll}
\hline \multirow{2}{*}{ Variable } & \multicolumn{2}{l}{ Mild $(10 \%)$} & \multicolumn{2}{l}{ Moderate $(20 \%)$} & \multicolumn{2}{l}{ Severe $(30 \%)$} \\
\cline { 2 - 7 } & $\begin{array}{l}\text { Overdue } \\
\text { rate }\end{array}$ & $\begin{array}{l}\text { Rise } \\
\text { ratio [\%] }\end{array}$ & $\begin{array}{l}\text { Overdue } \\
\text { rate }\end{array}$ & $\begin{array}{l}\text { Rise } \\
\text { ratio [\%] }\end{array}$ & $\begin{array}{l}\text { Overdue } \\
\text { rate }\end{array}$ & $\begin{array}{l}\text { Rise } \\
\text { ratio [\%] }\end{array}$ \\
\hline NGDP & 0.001880 & 13.70 & 0.002138 & 29.27 & 0.002431 & 46.97 \\
CPI & 0.001722 & 4.14 & 0.001794 & 8.46 & 0.001868 & 12.95 \\
S & 0.001670 & 1.00 & 0.001687 & 2.01 & 0.001704 & 3.03 \\
\hline
\end{tabular}

The results in Table 3 show that control the other variables, the percentages of overdue loans of small loan companies rose by $13.70 \%, 29.27 \%$ and $46.97 \%$ under the pressure of $10 \%, 20 \%$ and $30 \%$ decrease in nominal GDP respectively. The percentages of overdue loans increased by $4.14 \%, 8.46 \%$ and $12.95 \%$ under the pressure of $10 \%, 20 \%$ and $30 \%$ increase in CPI respectively. The percentages of overdue loans increased by $1.00 \%, 2.01 \%$ and $3.03 \%$ under the pressure of $10 \%, 20 \%$ and $30 \%$ increase in the total retail sales of social consumer goods respectively. It is not difficult to find that while other factors remain unchanged, the growth rate of nominal GDP has the greatest impact on the overdue loan ratio, and the impact of retail sales of social consumer goods on the overdue loan ratio is very small. Obviously, the macroeconomic impact on credit risk of small loan companies has a more significant impact, reflecting the resistance of micro-finance company's industry system against macroeconomic risk impact is limited. In carrying out internal risk control and regulatory oversight, micro-finance companies should pay attention to the macroeconomic changes and take precautionary measures in advance to effectively control risks and enhance the industry stability of the micro-finance companies.

\section{Conclusion}

We summarizes the results and experience of financial system stress testing, designs a framework model of macro-stress testing for micro-credit companies based on previous researches, and conducts tests on the data of Zhejiang Province. The test results show that macroeconomic has a significant impact on the credit risk of small loan companies. When the nominal GDP growth rate drops by $30 \%$, the overdue loan lending rate of small loan companies may increase by $46.97 \%$. However, the rise of the CPI index and the decline of the total retail sales of social consumer goods have not obvious influence on small loans companies.

Therefore, when monitoring the risk of micro-loan companies, the management should pay attention to the possible macroeconomic fluctuations and make precautionary measures in light of the possible fluctuations in order to maintain the stability of the micro-financial sector in advance.

\section{References}

[1] L.Y. Zhang, J. Yang and E.J. Cheng: Financial Research, Vol.432 (2016) No.6, p.142.(In Chinese)

[2] H.J. Liu: Modern Business,(2016) No.34, p.78.(In Chinese)

[3] X. Yan and J.L. Lu: China economy and trade guide, (2010) No.16, p.65. (In Chinese)

[4] W.D. Chen, X.G. Zhang and Q.Y. Xiong: Financial Regulatory Research, (2015) No.10, p.1. (In Chinese)

[5] Pesola J: Bank Of Finland Discussion paper, (2000) No.2, p.457.

[6] Deventer DV, Kenji I: Credit risk models and the Basel Accords (RENMIN University of China Press, China, 2003), p.14

[7] Rodriguez, Adolfo, Trucharte, Carlos: Journal of Financial Stability, (2007) No.3, p.87.

[8] Wilson T: Risk, Vol.10 (1997) No.9, p.56. 
[9] Wilson T: Risk, Vol.10 (1997) No.10, p.111.

[10] Berkowitz J.: Ssrn Electronic Journal, Vol.2 (1999) No.2.

[11] Boss M.: Financial Stability Report, (2002) No.4, p.64.

[12] Virolainen K.: Bank of Finland, mimeo, Vol.19 (2004) No.1, p.1.

[13] Kearns A.: Financial Stability Report, (2004). p.111.

[14] Wong J H-Y, Choi K-F and Fong P-W.: The Journal of Risk Model Validation, Vol.1 (2008) No.2, p.3.

[15] Sanvi Avouyi-Dovi.: Banque of France. (2009) No.238.

[16] S.S. Ba and Y.Q. Zhu: Economist, (2010) No.2, p.70.(In Chinese)

[17] J. Yin and S. Liu: Finance and Economics Theory and Practice, Vol.32 (2011) No.1, p.13. (In Chinese)

[18] J.G. Peng, H. Yi and L.Y. Pan: Management Science in China, Vol.23 (2015) No.4, p.11. (In Chinese)

[19] J.J. Shi and Y. Zhou: Journal of Central University of Finance and Economics, (2011) No.10, p.42. (In Chinese)

[20] S.G. Yang and Y.Z. Liu: Journal of Jishou University, Vol.36(2015) No.6, p.30.(In Chinese)

[21] Working Group on Environmental Stress Test of Industrial and Commercial Bank of China, Y.Q. Zhou, J. Ma, H. Yin, S.H. Ma, Y. Yue, X. Yang and M.Y. Qiu: Financial Forum, Vol.21 (2016) No.2, p.3.(In Chinese)

[22] S.Y. GAO, Q. XU and N. SHEN: Journal of Tianjin University of Finance and Economics (Natural Science), Vol.36(2016) No.2, p.77.(In Chinese)

[23] J.C. Ding, Y.X. Liu and N. Chen: New Economics, (2016) No.2, p.83. (In Chinese)

[24]X.Q. Tan: Finance and Economics, (2017) No.8, p.109.(In Chinese)

[25] Y. Fang: Economic Theory and Business Management, (2017) No.2, p.48. (In Chinese)

[26] Y.M. Zhou: Management Review, Vol.26 (2014) No.9, p.58.(In Chinese)

[27] Y. Zhang and N. Duan: China Financial Regulatory Research, (2015) No.1, p.69.(In Chinese)

[28] Y.X. Gao: Journal of Yulin University, Vol.26 (2016) No.1, p.41. 